\title{
ASSESSMENT OF THE LEVEL OF STUDENTS' PERCEPTION OF HO CHI MINH THOUGHT ABOUT SOCIALISM AT SOME UNIVERSITIES IN HO CHI MINH CITY, VIETNAM
}

PHUONG NGO TUAN

Faculty of Philosophy, Ho Chi Minh City University of Social Sciences and Humanities, Vietnam

\section{ABSTRACT}

Ho Chi Minh's ideology on Socialism in Vietnam includes product development and social progress in culture, politics, economy, and society, building people for comprehensive development. The study's purpose is to assess students' perceptions of Ho Chi Minh's thoughts about Socialism at some universities in Ho Chi Minh City. The study subjects include 242 students (68 males, 174 females) aged 18 to 24, studying at universities in Ho Chi Minh City. Statistical methods used in the study include: Mean, Correlation comparison, T-test, Anova to show the difference between male, female and school year of the level of students' perception of Ho Chi Minh thought about Socialism. The results indicate a gender and grade difference between students' perception of Ho Chi Minh's thought about Socialism. This result is essential. It aims to propose some solutions such as improving the legal system and policy, improving the quality of teaching Ho Chi Minh Thought subject to students.

KEYWORDS: Ho Chi Minh's Ideology, Students, Socialism, University

Received: Oct 07, 2020; Accepted: Oct 27, 2020; Published: Nov 09, 2020; Paper Id.: IJMPERDOCT202031

\section{INTRODUCTION}

Ho Chi Minh's thought on Socialism in Vietnam includes: defining the goal of building a developed, civilized and progressive society, as well as the methods and principles of implementation to achieve the above goal(Nguyen Huu, 2019); setting the aim of building a fully formed human being following the national cultural tradition (Pham, 2020). This is the foundation for the formation and the development of Ho Chi Minh's thought on national independence associated with Socialism, which serves as a magnetic needle for the Vietnamese revolution (Hoang Trang, 2004; Linh, 2009). Similarly, Pham (2020) also showed the substance and role of national solidarity towards forming a developed, civilized, and progressive society. Thanh Duy's research $(2001 ; 2002)$ indicated that the role and significance of creating and enhancing the human factor in building a modern society, including fostering intelligence, ethical qualities, lifestyle, and taking care of material interests, etc. Therefore, the State needs to inherit and apply Ho Chi Minh's ideology to build the nation and develop plans, policies, and laws to protect equal rights(Van Dung, 2019). That is a clean and robust Vietnamese socialist rule-of-law state, by the people and for the people (Nguyen, 1998)

According to the research by author NguyenNguyen Thi et al. (2019), Ho Chi Minh's thought has apparent effects on the thinking of young people, especially students (Nguyen Thi et al. (2019). Vietnamese students are the ones that have consistent goals, independence; they can absorb the essence of humanity, creative thinking; own the capacity to master knowledge; have good health and patriotism; and are always willing to protect 
the country(Van, 2020). Ho Chi Minh's thought is a torch to lead young people towards optimistic thoughts and good virtues, contributing to building and defending the Fatherland(Nguyen Thi et al., 2019). In Vietnam, there have been many kinds of research related to Ho Chi Minh's ideology on the construction of Socialism, such as an overview of the process of forming Ho Chi Minh's thought on Socialism; Analysis of content on national independence associated with Socialism as well as Ho Chi Minh's thought on the road to Socialism. However, no previous research has investigated the level of students' perception of Ho Chi Minh's ideology on Socialism in Vietnam as far as we know. This work aims to fill the above gaps, thereby confirming Ho Chi Minh's historical significance in Socialism in Vietnam. With this aim in mind, in this paper, we present proposed solutions for promoting the realization of Ho Chi Minh's thought on Socialism in the Vietnamese student community - Future knowledge team, to build a new society that is more advanced, civilized, and progressive. Simultaneously, research is also the basis for functional agencies to plan human development strategies in developing Socialism in Vietnam.

\section{According to the Research Objectives of the Topic, there are Three Hypotheses:}

$\mathbf{H}_{1}$ : There is a correlation between the factors of Ho Chi Minh's thought about Socialism.

$\mathbf{H}_{2}$ : There is a difference between male and female students on the level of perception of Ho Chi Minh's thoughts about Socialism.

H3: There is a difference between the school years among the students on the perception of Ho Chi Minh's thought about Socialism.

\section{METHODS}

\section{Participants}

Table 1: Information on study demographics

\begin{tabular}{|c|c|c|}
\hline & & $n(\%)$ \\
\hline \multirow{2}{*}{ Gender } & Male & $68(28.1)$ \\
\hline & Female & $174(71.9)$ \\
\hline \multirow{4}{*}{ School year } & Freshman & $4(1.7)$ \\
\hline & Sophomore & $170(70.2)$ \\
\hline & Junior & $32(13.2)$ \\
\hline & Senior & $36(14.9)$ \\
\hline \multirow{4}{*}{ University } & University of Education & $76(31.4)$ \\
\hline & University of Social & $85(35.1)$ \\
\hline & $\begin{array}{l}\text { Sciences and Humanities } \\
\text { International University }\end{array}$ & $32(13.2)$ \\
\hline & University of Architecture & $49(20.2)$ \\
\hline
\end{tabular}

Note: n: Frequency; \%: Percent

A convenient sampling method is used to select students to volunteer to help research and administer the survey. The survey tool was distributed to 250 participating Vietnamese students at four universities in Ho Chi Minh City, Vietnam, including the University of Education, the University of Social Sciences and Humanities, International University, and the University of Architecture. Two hundred forty-two survey forms were returned, with a return rate of 96.8\%, exceeding the 30\% response rate most researchers requested for analysis (Dillman DA, 2000; Dillman, D. A., Hao, F., \& Millar, 2017). In which, there were 68 males (28.1\%) and 174 females (71.9\%). The distribution among year students included: 4 Freshmen (1.7\%), 170 Sophomores (70.2\%), 32 Juniors (13.2\%) and 36 Seniors (14.9\%). Table 1 shows the distribution of study participants. 


\section{Measure}

All study participants voluntarily agreed to participate in a 2-part questionnaire. Part 1: Gender, School year, University. Part 2: Evaluating the level of students' perception of Ho Chi Minh's thought about Socialism with 18 criteria. The subjects were asked to rate based on a 5-level Linkert scale: $1=$ Strongly disagree to $5=$ Strongly agree. The assessment is based on a total score of 18 criteria. The higher the score, the higher the student's awareness of Ho Chi Minh's thought about Socialism and vice versa. The confidence coefficient of the total Cronchbach's Alpha scale is .97, and that of the criteria ranges from .82 to 0.93 . The Cronbach alpha reliability for the scales is as follows: 1: The State needs to promote people's ownership to mobilize their positivity and creativity in the cause of socialism construction (5 items): .90; 2: Socialism has a highly developed economy, based on modern productive forces and the public regime of the primary means of production, in order to continually improve the material and spiritual life of the people, especially the labouring people (3 items): .86; 3: Socialism is a highly developed society in culture and morality (4items): .90; 4: Socialism is a just and just society (2 items): .82; 5: Socialism is the people's collective work, built by the people under the Party's leadership (4 items): .93. Available evidence shows that the scale has high reliability, which is suitable for use in research. Besides, we also used the expert interview method better to understand Ho Chi Minh's thoughts on Socialism.

\section{Analyses}

All participants were provided informed consent after receiving an explanation of the purpose of the research. The Statistical Package for the Social Sciences (SPSS) version 20 was used for data analyses. To evaluate the prediction score; regression, through the implementation of independent sample t-test, Anova score on the assessment of the level of students' perception of Ho Chi Minh thought about Socialism at some universities in Ho Chi Minh City, Vietnam.The coding procedure was performed as follows: $1=$ Strongly disagree, $2=$ Disagree, $3=$ Slightly agree, $4=$ Agree, $5=$ Strongly agree. To transform the discrete values into ranks, distance value was calculated as $($ Maximum $-\mathrm{Minimum}) / \mathrm{n}=$ (5-1)/5 = 0.8(Jaafar, M. H., Arifin, K., Aiyub, K., Razman, M. R., \& Kamaruddin, 2017)

\section{RESULTS}

Table 2: Average, standard deviation, correlation

\begin{tabular}{|c|c|c|c|c|c|c|c|}
\hline Variable & $\mathbf{M}$ & $\mathbf{S D}$ & $\mathbf{1}$ & $\mathbf{2}$ & $\mathbf{3}$ & $\mathbf{4}$ & $\mathbf{5}$ \\
\hline $\mathbf{1}$ & 1.91 & .44 & 1 & & & & \\
\hline $\mathbf{2}$ & 1.15 & .28 & $.78^{* *}$ & 1 & & & \\
\hline $\mathbf{3}$ & 1.56 & .38 & $.80 .^{* *}$ & $.79^{* *}$ & 1 & & \\
\hline $\mathbf{4}$ & 8.00 & .19 & $.78^{* *}$ & $.78^{* *}$ & $.81^{* *}$ & 1 & \\
\hline $\mathbf{5}$ & 1.56 & .37 & $.85^{* *}$ & $.86^{* *}$ & $.85^{* *}$ & $.85^{* *}$ & 1 \\
\hline
\end{tabular}

Note:**P $>0.01 ;$ M: Mean; SD: Standard Deviation

The mean score for category 1 was $1.91(\mathrm{SD}=.44)$. The mean score for category 2 was $1.15(\mathrm{SD}=0.28)$. The score for category 3 was $1.56(\mathrm{SD}=.38)$. The one for category 4 was $8.00(.19)$ and for category 5 was $1.56(\mathrm{SD}=.37)$. Table 3 shows the correlation coefficients between categories $1 ; 2 ; 3 ; 4$, and 5 . The correlation coefficient for category 1 ranges from .78 to .85 . The correlation coefficient for category 2 ranges from .79 to .86. The strongest correlation was found in pairs 2 and $5(\mathrm{r}=.86, \mathrm{p}<0.01)$, items 1 and 5 with category $\mathbf{3}$ and $\mathbf{4}$, category $\mathbf{4}$ and $\mathbf{5}$ have the same correlation coefficient $(r=.85, p<0.01)$. All sub-scenes of the scale have positive correlation $(r=.78, p<0.01)$ to $(r=.86 . p<0.01)$. 
Table 3: DeterminationT-test and ANOVA results for gender and school year

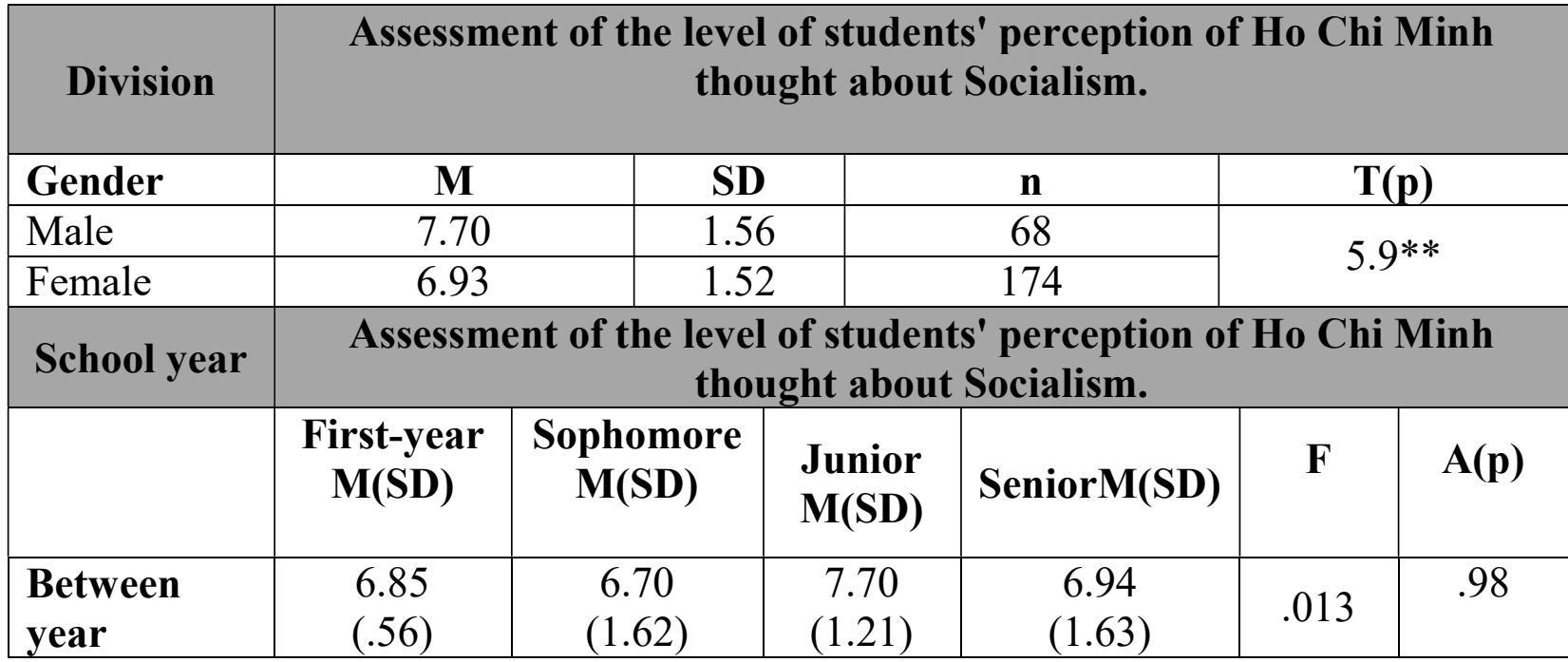

Note: $\mathrm{P}>0.01 * *$

This section outlines the results of the study that there was a significant difference in the scores for male $(\mathrm{M}=$ $7.70, \mathrm{SD}=.70)$ and no difference for female $(\mathrm{M}=6.93, \mathrm{SD}=1.52) ; \mathrm{t}(240)=.63, \mathrm{p}>0.01$. Thus, hypothesis $\mathbf{H}_{2}$ : There is a difference between male and female students in the level of awareness of Ho Chi Minh's thought about Socialism. Oneway ANOVA among subjects was performed to compare the students' perception of Ho Chi Minh's thought about Socialism. There is no difference between the school years in the level of awareness of Ho Chi Minh's ideology on socialism level $\mathrm{p}>0.01$ in the condition $[\mathrm{F}(3,238)=0.013, \mathrm{p}>0.01]$. The comparison between the year-to-year average points: freshman $(M=6.85, \mathrm{SD}=.56)$, sophomore $(M=6.70, \mathrm{SD}=1.62)$, Junior $(M=7.70, \mathrm{SD}=1.21)$, Senior $(M=6.94$, $\mathrm{SD}=1.63$ ) indicates that there is no significant difference in the level of students' perception of Ho Chi Minh thought about Socialism. Rebuttal of hypothesis $\mathbf{H}_{3}$ : There is a difference between the school years among the students on the perception of Ho Chi Minh's thought about Socialism.

\section{DISCUSSIONS}

The present study's main goal was to assess students' perception of Ho Chi Minh's thought about Socialism at some universities in Ho Chi Minh City, Vietnam, at an acceptable level. The main findings indicated that there was a positive correlation between the five sub-scenes including 1: The State needs to promote people's ownership to mobilize their positivity and creativity in the cause of socialism construction; 2: Socialism has a highly developed economy, based on modern productive forces and the public regime of the primary means of production, in order to constantly improve the material and spiritual life of the people, especially the labouring people; 3: Socialism is a highly developed society in culture and morality; 4: Socialism is a just and just society; 5: Socialism is the people's collective work, built by the people under the Party's leadership. All the sub-scenes have a positive correlation and a close relationship with each other. This study is similar to the Party's document, "Promoting democracy must be associated with discipline as well as strengthening the legislation, enhancing civic responsibility, and social ethics." Alongside paying attention to creating a modern society with Vietnamese people possessing all the characteristics of virtue, intellect, health, and beauty, the Congress affirmed: "Renovating basically and comprehensively in education and training; developing human resources" as well as "Building, progressing culture and people" (Communist Party of Vietnam, 2010). Hence, there is a close relationship between the factors. Thus, hypothesis $\mathbf{H}_{\mathbf{1}}$ is accepted: There is a correlation between the factors of Ho Chi Minh's ideological system 
about Socialism. The second research objective of the thesis showed no difference in male and female students' awareness of Ho Chi Minh's thoughts on Socialism. The research by Pham (2020), it pointed out the role of community development, national solidarity, and efforts. It is crucial to appreciate the role of human beings and the importance of building people, including fostering intelligence, ethical qualities, lifestyles, and caring for human material interests(Thanh Duy, 2001, 2002). The ideology of Ho Chi Minh is a torch that guides youngsters towards positive thoughts and good virtues, aiming to construct and protect the Fatherland (Thi et al., 2019). Besides, Vietnamese students, with their bravery, qualifications, and acumen in absorbing the quintessence of humanity, are the core force in the socialism building revolution. Accordingly, the State needs to come into and apply Ho Chi Minh's ideology to the nation's construction, especially the student generation, because this generation has a revolutionary idea, a steadfast goal of national independence and Socialism, the ability to absorb the quintessence of human culture, creative thinking, the ability to master scientific knowledge and modern technology as well as has good practice skills and good health to build and defend the country (Van, 2020). Thereby, the Youth Union and Association movements and extracurricular activities, become the special ones of student generations, which creates an environment for students to practice, strive, and grow. For instance, there are many revolutionary action movements such as "Youth volunteers," "Vanguard Youth in the cause of national construction and defence," "Youth career," "Youth in keeping the nation," "Youth creation," "Relay exam season," "Student of Five Merits," "Students with the country's sea, the island"; contest writing and composing the song "Vietnamese students with beautiful stories," "The subjects of political theory." All students have an equal right to participate in the above activities, movements, and subjects as a prerequisite. Through the above activities, it shows no difference between male and female students and between the students in the school years in perception of Ho Chi Minh's thought about Socialism. Thus, the research results reject the hypothesis $\mathbf{H}_{2}$ : There is a difference between male and female students on the level of perception of Ho Chi Minh's thought about Socialism, and also reject the hypothesis $\mathbf{H}_{3}$ : There is a difference between the students in the school years on the level of perception of Ho Chi Minh's thought about Socialism. Ho Chi Minh's thought on Socialism in Vietnam has been put into practice through disciplines and movements, which contributes to the establishment of desire and aspiration for ideals, ambitions, life attitudes, and ethical lifestyles following Vietnam's social value orientation and application in practice of each student(Van, 2020). According to MA Ngo Quang Huy, "One of the reasons hindering students' perception of Ho Chi Minh's thought about Socialism is the excessive painting of President Ho Chi Minh's image to serve political purposes. This inadvertently sanctifies Ho Chi Minh's patriotism, making it far away from the current student generation, while patriotism is one of their unique qualities.". In summary, the above research results have shown the aspects including a positive correlation, no difference between genders, and between students from the school years in the perception of Ho Chi Minh's thought about Socialism. However, the study has still presented some limitations, such as only assessing students at the level of perception of Ho Chi Minh's ideology on Socialism besides building a developed, civilized and progressive society. The research aims to find solutions to raise Vietnamese students' awareness of forming a new society with development, civilization, progression towards Socialism. Simultaneously, it also contributes to stimulating and promoting further research on this topic in the future. The results are intended to provide a more detailed and general insight into the historical significance of Ho Chi Minh's thoughts on Socialism in Vietnam.

\section{CONCLUSIONS}

The present findings have evaluated students ' understanding of Ho Chi Minh's thought about Socialism at several universities in Ho Chi Minh City, Vietnam, at an appropriate level. Our data indicate that there is a connection between the factors of Ho Chi Minh's thought about Socialism, and simultaneously, the discrepancies between genders and school years 
also occur in this research. To our knowledge, this is the first report investigating the level of students' perception of Ho Chi Minh's thoughts about Socialism at some universities in Ho Chi Minh City, Vietnam. Besides, the research results can be used as a reference for teaching, research, and studying at universities and supporting the authorities in planning guidelines, policies, and measures to build Socialism in Vietnam successfully.

\section{REFERENCES}

1. Communist Party of Vietnam. (2010). Document of the 12th Central Executive Committee, Session X.

2. Dillman, D. A., Hao, F., \& Millar, M. M. (2017). Improving the effectiveness of online data collection by mixing survey modes. The SAGE Handbook of Online Research Methods, 220-238.

3. Dong, N. H. (2019). Building developed Socialism in Vietnam. Journal of the Central Propaganda Department.

4. Hoang Trang, P. N. A. (2004). Ho Chi Minh's thought on national independence associated with Socialism in Vietnam. Labor Publishing House.

5. Jaafar, M. H., Arifin, K., Aiyub, K., Razman, M. R., \& Kamaruddin, M. A. (2017). Human Element as the Contributing Factor Towards Construction Accidents from the Perspective of Malaysian Residential Construction Industry. In International Conference on Applied Human Factors and Ergonomics.

6. Linh, N. . (2009). The dialectic relationship between national independence and Socialism in Ho Chi Minh thought. National Political Publishing House.

7. Loc, N. D. (1998). Ho Chi Minh's Thought about the State of the people, by the people, for the people. National Political Publishing House.

8. Pham, N. L. (2020). Ho Chi Minh 's Thought on Community Development Through the Literary Work “Mass Mobilization ” Thought on Community Development Through the Work “ Mass Mobilization .” 8(3), 68-74. https://doi.org/10.11648/j.ijp.20200803.12

9. Thanh Duy. (2001). Ho Chi Minh's Thought with the cause of building fully developed Vietnamese people. National Political Publishing House.

10. Thanh Duy. (2002). Ho Chi Minh's Thought with the cause of building fully developed Vietnamese people. National Political Publishing House.

11. Thi, N., Minh, H., Ph, D., Valdez, M. L. A., \& Ph, D. (2019). Ideologies Reflected in the Selected Speeches of Ho Chi Minh. International Journal on Studies in English Language and Literature, 7(4), 17-28. https://doi.org/10.20431/23473134.0704002

12. Van Dung, V. (2019). Ho Chi Minh's thoughts on Women's Equal Rights. European Journal of Political Science Studies., 3(1), $159-168$

13. Van, M. T. T. (2020). Revolutionary ideal education for students in universities. Universities. Journal of the Central Propaganda Department. [http://tuyengiao.vn/bao-ve-nen-tang-tu-tuong-cua-dang/giao-duc-ly-tuong-cach-mang-cho-sinhvien-tai-nha-truong-12710] 